\title{
Fabrication and Evaluation of 2-Hydroxyethyl Methacrylate-co-Acrylic Acid Hydrogels for Sustained Nicorandil Delivery
}

\author{
Ayesha Rashid, Mahmood Ahmad*, Ume Ruqia Tulain and Furqan Muhammad \\ lqbal \\ Faculty of Pharmacy and Alternative Medicine, The Islamia University of Bahawalpur, Bahawalpur, Pakistan
}

*For correspondence: Email: ma786_786@yahoo.com; Tel: 011-92-062-9255565, 0300-9682258; Fax: 011-92-062-9255565

Received: 25 February 2015

Revised accepted: 16 June 2015

\begin{abstract}
Purpose: To fabricate and evaluate oral 2-hydroxyethyl methacrylate-co-acrylic acid hydrogels as a drug delivery system for sustained release of nicorandil.

Methods: HEMA-co-AA hydrogels using different monomer concentrations were prepared by free radical polymerization. $\mathrm{N}, \mathrm{N}$-methylene bis acrylamide (MBA) was used as crosslinker and potassium persulphate (KPS) as initiator. Nicorandil $(20 \mathrm{mg})$ loaded hydrogels were characterized by Fourier transform infrared spectroscopy (FTIR), thermogravimetric analysis and differential scanning calorimetry (DSC) and scanning electron microscopy (SEM). Swelling ratio, equilibrium swelling (ES), gel content (gc), porosity measurement $(P)$ and in vitro drug release of the delivery system were evaluated.

Results: Swelling ratio and ES decreased as AA concentration (\%) was reduced from 3.173 to 2.93 ( $p H$ 1.2) and 16.42 to 15.01 ( $p H$ 7.4) and 68.49 to 65.90 (pH 1.2) and 93.91 to 93.34 ( $p H$ 7.4), respectively, while HEMA and MBA showed opposite effects. Gel content (\%) and porosity (\%) ranged from 83.76 to 88.0, respectively from $F 1$ to $F 9$. With increase monomer content $(A A)$, drug release increased from 85.99 to $89.38 \%$. However, when the concentrations of HEMA and MBA were raised, drug release decreased.

Conclusion: HEMA-co-AA hydrogels are potential $\mathrm{pH}$-sensitive and sustained-release system for nicorandil.
\end{abstract}

Keywords: Hydrogel, 2-Hydroxyethyl methacrylate-co-acrylic acid, Sustained drug release, Monomer, Nicorandil, Swelling ratio, Porosity

\begin{abstract}
Tropical Journal of Pharmaceutical Research is indexed by Science Citation Index (SciSearch), Scopus, International Pharmaceutical Abstract, Chemical Abstracts, Embase, Index Copernicus, EBSCO, African Index Medicus, JournalSeek, Journal Citation Reports/Science Edition, Directory of Open Access Journals (DOAJ), African Journal Online, Bioline International, Open-J-Gate and Pharmacy Abstracts
\end{abstract}

\section{INTRODUCTION}

Due to health-related dysfunctions, drug delivery to target site at therapeutic levels for a prolonged period is a major objective. However, the action of pharmaceutical agents is confined by several factors including drug degradation, interaction with cells and inability to infiltrate tissues. These factors provide the basis for developing carrier systems with the desired release profile with regard to time and drug distribution [1]. For oral controlled release drug delivery systems hydrophilic gel forming polymeric systems are extensively used to achieve the anticipated drug release profile, cost effectiveness and broad regulatory acceptance [2]. 
Graft copolymers have been extensively used to formulate a number of controlled release systems such as hydrogels, microspheres, matrix tablets. 'Grafting' refers to a technique in which monomers are covalently bonded onto the polymer chain. Graft copolymerization can change the properties of polymer. These are extensively used in various areas such as dyeing, printing, fiber strength, chemical resistance, water repellency, crease resistance and abrasion resistance [3]. Grafting imparts the desired modifications in reactants during preparation. These grafted co-polymeric systems are of great interest as they can be formulated into various stimuli-dependent controlled release drug delivery systems [4].

Nicorandil, a nicotinamide derivative, is an efficacious remedy in the management of hypertension and angina pectoris. As a potassium channel opener, it causes vasodilatation of arterioles and large coronary arteries. Venous vasodilatation is attributed to its nitrate component [5]. The aim of this study was to prepare 2-hydroxyethyl methacrylate-coacrylic acid hydrogels and to formulate a hydrogel drug delivery system for prolonged drug delivery and greater therapeutic efficiency.

\section{EXPERIMENTAL}

\section{Materials}

Acrylic acid (99 \%) was purchased from Sigma Aldrich-Netherlands; 2-hydroxyethyl methacrylate (97 \%) from Sigma Aldrich-Germany and N, N methylene-bis-] acrylamide (98\%) purchased from Fluka-Switzerland. Potassium persulphate (99\%, AnalaR, BDH, England), potassium dihydrogen phosphate (98 - $100 \%$, Merck, Germany), absolute ethanol (Merck, Germany), and nicorandil (99.8 \%, a gift from Getz PharmaPakistan) were also used in the study.

\section{Synthesis of hydrogel by free radical polymerization}

Hydrogels were prepared by free radical polymerization. Acrylic acid solution was placed on a hot plate with a magnetic stirrer at $70{ }^{\circ} \mathrm{C}$ and stirring was continued at $300 \mathrm{rpm}$. Initiator (KPS) solution was added drop wise to the solution at the same temperature and stirring speed. These conditions were maintained for 10 $\mathrm{min}$, and the solution allowed to cool down to room temperature. 2-Hydroxyethyl methacrylate and $\mathrm{N}, \mathrm{N}$, methylen-bis-acrylamide solution were added to the mixture and stirred at $300 \mathrm{rpm}$ for 1 - 2 min before maintaining at $80{ }^{\circ} \mathrm{C}$ for $3 \mathrm{~h}$ in a water bath to allow polymerization. The resulting hydrogel was cut into small discs of $4 \mathrm{~mm}$ thickness with a sharp cutter, washed with distilled water, placed in an ethanol: water (50:50) mixture for $24 \mathrm{~h}$ before drying in an oven at $46{ }^{\circ} \mathrm{C}$ until equilibrium was achieved.

\section{Swelling studies}

Swelling studies were performed at $\mathrm{pH}$ 1.2, 5.8 and 7.4 till swelling equilibrium, at prescheduled time points. A weighed disc of the formulation was socked in $100 \mathrm{ml}$ buffer of $\mathrm{pH} 1.2,5.8$ and 7.4 separately. At specific time points, the discs were dried by using blotting paper and weighed with an analytical balance.

Dynamic swelling and equilibrium swelling ratios of all formulations were determined using Eq 1 .

$\mathrm{Q}=\mathrm{W}_{\mathrm{h}} \mathrm{W}_{\mathrm{d}}$

where " $q$ " is dynamic swelling, $W_{h}$ shows swollen gel's weight at time $t$ and $W_{d}$ shows initial weight of dried hydrogel disc [6].

\section{Equilibrium swelling measurement}

Swelling measurement was carried out until equilibrium weight of the gel was achieved. Equilibrium swelling was calculated as shown in Eq 2.

$\mathrm{ES}(\%)=(\mathrm{Meq}-\mathrm{Mo}) / \mathrm{Meq} \times 100$

Where Meq = mass of the swollen gel at equilibrium and Mo the mass of dried gel disc [7].

\section{Gel content determination}

Freshly prepared hydrogel disc of $4 \mathrm{~mm}$ thickness (was subjected to vacuum oven drying at $45{ }^{\circ} \mathrm{C}$ to a constant weight $\left(\mathrm{W}_{\mathrm{o}}\right)$. Then extraction was performed with deionized water for $24 \mathrm{~h}$. Non reacted polymer/monomer was washed away via this extraction. The disk was again dried in oven at $45{ }^{\circ} \mathrm{C}$ till constant weight $\left(\mathrm{W}_{1}\right) . \%$ gel content was determined by equation 3.

$\% g c=\left(W_{1} W_{0}\right) \times 100$

where $W_{1}$ is the weight of dry gel after extraction in distilled water and $W_{0}$ is the initial weight of the dry gel [8].

\section{Porosity measurement}

This entailed computing the fraction of voids volume over total volume between 0 and 1 or in 
case of percent between 0 to $100 \%$ is stated as porosity. Solvent replacement method was chosen to figure out porosity measurement. The dried weighed hydrogel disc (Md) was immersed in absolute ethanol for $24 \mathrm{~h}$ (to constant weight). After $24 \mathrm{~h}$ hydrated hydrogel disc was blot dried to remove excess surface ethanol and weighed on analytical weight balance (Wh). Porosity $(P)$ was computed as in $\mathrm{Eq} 4$.

Porosity $(\%)=(M h-M d) / \rho V \times 100$

where $\rho$ refers to density of absolute ethanol and $\mathrm{V}$ is hydrogel volume [9].

\section{Drug loading determination}

Drug loading was determined by absorption method. A solution (1\%) of the drug in phosphate buffer ( $\mathrm{pH} 7.4)$ was prepared. One disc of each formulation was allowed to swell and reach swelling equilibrium in $100 \mathrm{ml}$ of $1 \%$ drug solution. After swelling equilibrium was achieved, the discs were removed from solution, washed out with distilled water to remove excess surface drug, allowed to air-dry at room temperature and then dried in an oven at $40{ }^{\circ} \mathrm{C}$ to constant weight [10]. Drug loaded in discs was determined as in Eq 5.

Drug loading $(\%)=\left\{\left(\mathrm{W}_{\mathrm{L}}-\mathrm{W}_{\mathrm{u}}\right) / \mathrm{W}_{\mathrm{u}}\right\} 100$

where $W_{L}$ is weight of dried drug loaded disk and $\mathrm{W}_{\mathrm{u}}$ is weight of dried unloaded disc [11].

\section{Fourier transform infrared spectroscopy (FTIR)}

The gel formulation was subjected to Fourier transform infrared analyzer (Bruker, Tensor 27, Germany) at $25{ }^{\circ} \mathrm{C}$ to determine drug - polymer compatibility. In this study, attenuated total reflectance (ATR) technology along with OPUS data collection software was employed to analyze FTIR spectra of the samples obtained Bruker FTIR (Tensor 27 series, Germany) system in the range of $500 \mathrm{~cm}^{-1}-4000 \mathrm{~cm}^{-1}$. For the transmission study, finely grounded solid sample was placed directly in the path of infrared (IR) beam as a thin film.

Thermal gravimetric analysis (TGA) and
differential scanning calorimetry (DSC)

Dried and ground sample of formulation F1 (0.5 g) was subjected to thermogrametric analysis and differential scanning calorimetry by sealing them in aluminum pans. Measurements were achieved at a rate $10^{\circ} \mathrm{C}$ per min, under nitrogen flow of $25 \mathrm{ml} / \mathrm{min}$, in the temperature range of 20 to $900{ }^{\circ} \mathrm{C}$. The standard uncertainty of the sample mass measurement was $\pm 1 \%$. Equipment calibration was accomplished with calcium oxalate supplied with the instrument [12].

\section{Scanning electron microscopy (SEM)}

The surface morphology of all combinations of hydrogel formulations was determined by a scanning electron microscope (Hitachi, S3400N). The samples were coated with gold by Hummer Sputter Coater [13].

\section{In vitro drug release studies}

In vitro drug release of hydrogel discs loaded with nicorandil was evaluated according to the specifications of United States Pharmacopeia by using USP apparatus II. The dissolution medium (900 ml, $0.1 \mathrm{M} \mathrm{HCl}, \mathrm{pH} 1.2,900 \mathrm{ml}$ or phosphate buffer, $\mathrm{pH} 7.4$ ) used was stirred at $50 \mathrm{rpm}$ at 37 ${ }^{\circ} \mathrm{C} \pm 0.5{ }^{\circ} \mathrm{C}$, and $5 \mathrm{ml}$ of aliquot was drawn at various intervals up to $24 \mathrm{~h}$ with an automated sample collector (T-DT7 Pharmatest, Germany), after filtering through sinter filters (10 $\mu \mathrm{m}$ pore size). After each sample withdrawal, fresh $5 \mathrm{ml}$ medium was added to maintain sink conditions. The samples were diluted to $50 \mathrm{ml}$ with fresh dissolution medium and analyzed at $225 \mathrm{~nm}$ using a UV-spectrophotometer (PTCF II Pharma Test, Germany). The drug release study was conducted in triplicate [14].

\section{Statistical analysis}

Statistical significance of difference was evaluated using Statistical Package for Social Sciences (SPSS) version 20.

\section{RESULTS}

\section{Swelling behavior}

Dynamic equilibrium swelling ratios and percent equilibrium swelling (\% ES) as depicted in Table 2 elaborated that in acidic medium with lower pKa less swelling occurred as compared to basic medium with higher $\mathrm{pKa}$ where swelling was more.

Table 1 cleared that as acrylic acid content increases swelling ratio and percent equilibrium swelling increases (F4 to F6) while both decreases with increase in cross linker concentration (F7 to F9). 
Table 1: Composition and comparative swelling ratios of HEMA-co-AA hydrogels using different concentrations components

\begin{tabular}{|c|c|c|c|c|c|c|c|c|c|}
\hline \multirow[t]{2}{*}{$\begin{array}{l}\text { Sample } \\
\text { code }\end{array}$} & \multirow[t]{2}{*}{$\begin{array}{l}\text { HEMA } \\
(\% \text { w/w) }\end{array}$} & \multirow[t]{2}{*}{$\begin{array}{c}\text { AA g } \\
(\% w / w)\end{array}$} & \multirow[t]{2}{*}{$\begin{array}{l}\text { MBA g } \\
(\% \mathrm{w} / \mathrm{w})\end{array}$} & \multicolumn{3}{|c|}{$\begin{array}{l}\text { Dynamic equilibrium } \\
\text { swelling ratio }(q)\end{array}$} & \multicolumn{3}{|c|}{$\begin{array}{c}\text { Equilibrium swelling (ES, } \\
\%)\end{array}$} \\
\hline & & & & $\begin{array}{l}\mathrm{pH} \\
1.2\end{array}$ & pH 5.8 & pH 7.4 & pH 1.2 & pH 5.8 & $p H 7.4$ \\
\hline F1 & 0.84 & 16.5 & 0.015 & 3.498 & 10.810 & 16.358 & 71.416 & 90.749 & 93.886 \\
\hline F2 & 1.68 & 16.5 & 0.015 & 3.190 & 9.635 & 14.824 & 68.661 & 89.621 & 93.254 \\
\hline F3 & 3.36 & 16.5 & 0.015 & 3.013 & 9.163 & 13.696 & 66.818 & 89.087 & 92.699 \\
\hline F4 & 2.52 & 14.5 & 0.015 & 3.173 & 10.508 & 15.013 & 68.491 & 90.483 & 93.909 \\
\hline F5 & 2.52 & 12.5 & 0.015 & 3.115 & 10.188 & 16.005 & 67.904 & 90.184 & 93.752 \\
\hline F6 & 2.52 & 10.5 & 0.015 & 2.932 & 9.397 & 16.42 & 65.897 & 89.359 & 93.339 \\
\hline F7 & 2.52 & 14.5 & 0.020 & 2.917 & 9.904 & 10.104 & 65.728 & 89.903 & 94.084 \\
\hline F8 & 2.52 & 14.5 & 0.025 & 2.805 & 8.986 & 9.066 & 64.349 & 88.872 & 93.362 \\
\hline F9 & 2.52 & 14.5 & 0.030 & 2.528 & 6.193 & 8.775 & 60.451 & 83.853 & 92.740 \\
\hline
\end{tabular}

Acrylic acid (AA), 2-hydroxyethyl methacrylate (HEMA), potassium persulphate (KPS), N,Nmethylene-bis-acrylamide (MBA)

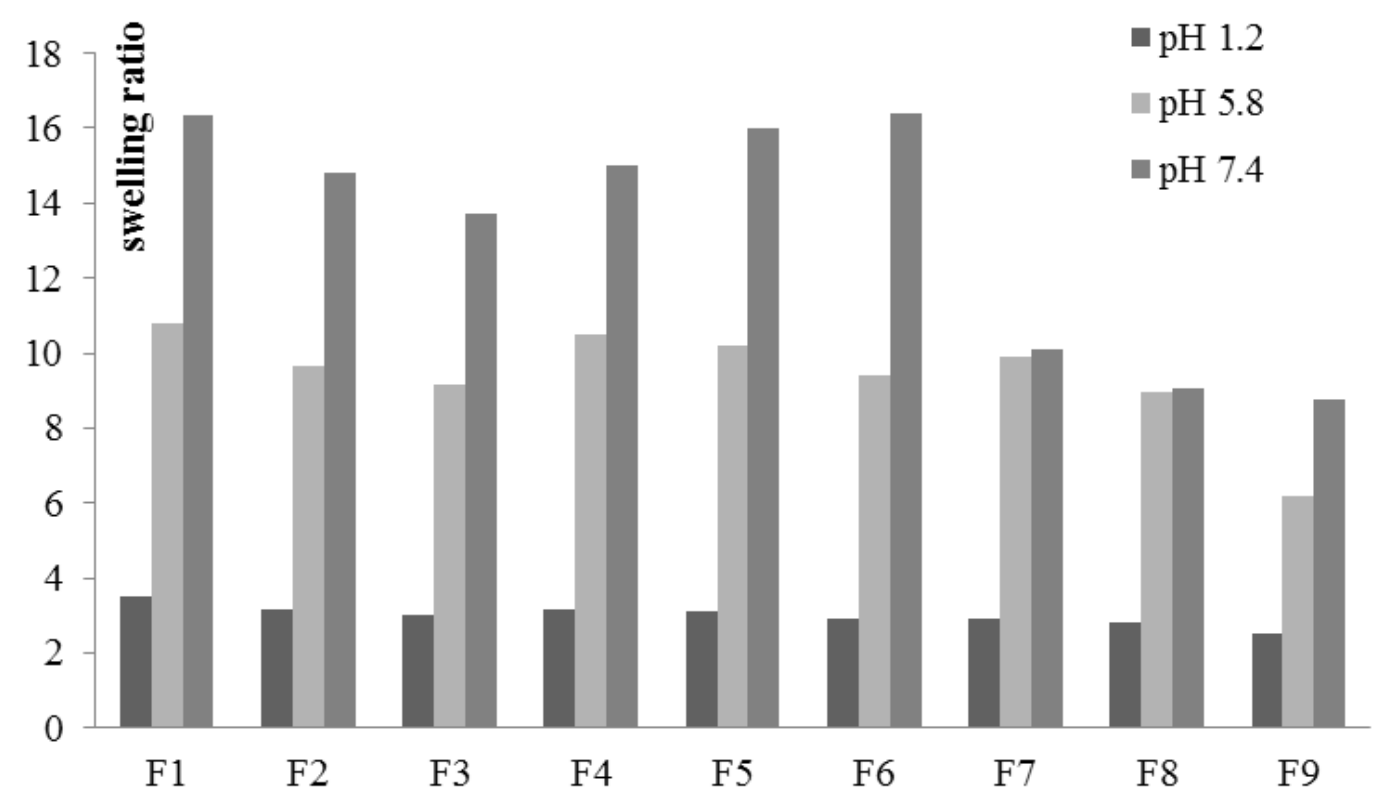

Figure 1: Swelling kinetics of formulations with varying weight ratio

\section{In vitro drug release}

Overall, in vitro drug release increased with increase in $\mathrm{pH}$ from acidic to basic (Figure 2).

Drug release was affected by change in monomer concentration and as well as by crosslinker concentration. At $\mathrm{pH}$ 7.4, drug release also increased with increase in acrylic acid concentration from 85.99 to $89.39 \%$ ( $p<$ $0.05)$ but decreased when HEMA level increased from 96.09 to $93.702 \%(p<0.05)$ and MBA concentration rose from 77.35 to $70.99 \%$ ( $p<$ 0.05).

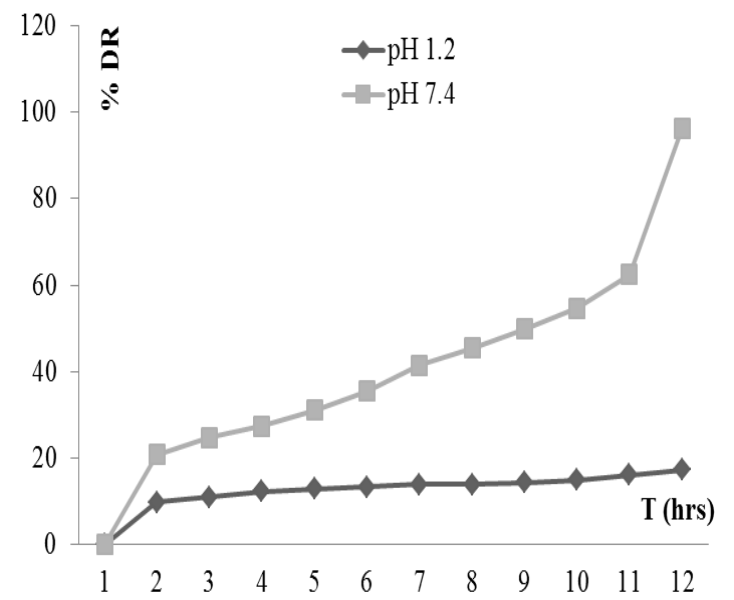

Figure 2: Cumulative release of nicorandil from HEMA-co-AA hydrogels 


\section{Gel content and porosity}

Percent gel content $\left(\% g_{c}\right)$ and percent porosity $(\% \mathrm{P})$ measurements of all formulations casing different concentrations of components computed. Percent gel content ranges from $83.758 \%$ to $87.988 \%(p<0.05)$ with different weight ratios. While percent porosity ranges from $14.425 \%$ to $5.3772 \%(p<0.05)$ with different weight ratios from F1 to F9.

\section{Drug - polymer compatibility}

The FTIR soectra showed drug excipient compatibility. Characteristic peaks were found at $3247 \mathrm{~cm}^{-1}$ for $(\mathrm{NH}) ; 1675 \mathrm{~cm}^{-1}$ for $(\mathrm{C}=\mathrm{O}, \mathrm{CONH})$ and $1362 \mathrm{~cm}^{-1}$ for $\left(\mathrm{CH}_{2}\right)$ [19]. Peaks were also observed at $3243.17 \mathrm{~cm}^{-1}$ for $(\mathrm{NH}) ; 1627.97 \mathrm{~cm}^{-1}$ for $(\mathrm{C}=\mathrm{O}, \mathrm{CONH})$ and $1361.55 \mathrm{~cm}^{-1}$ for $\left(\mathrm{CH}_{2}\right)$. In pure nicorandil sample peaks were observed at $1625.16 \mathrm{~cm}^{-1}, 1285.90 \mathrm{~cm}^{-1}$ and $705.33 \mathrm{~cm}^{-1}$ which are characteristic peaks of nicorandil. These characteristic peaks of nicorandil are also present in drug loaded hydrogel formulation (F1) showing stability of drug with hydrogel formulation.

\section{Morphology of hydrogels}

The results of scanning electron microscopy (SEM) are shown in Figure 4. Interconnected porous network structure of formulation $\mathrm{F} 1$ was observed in SEM microgram.

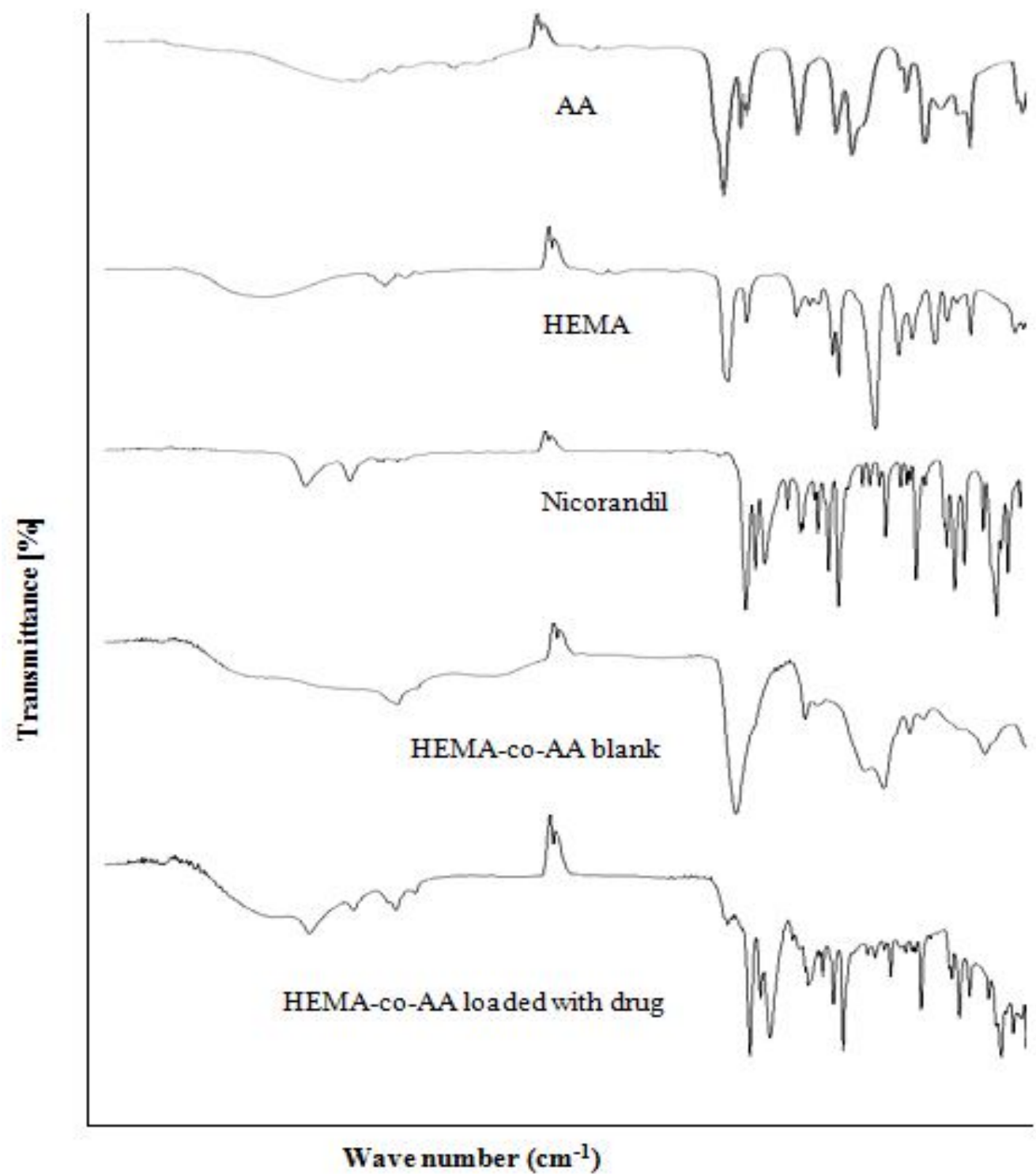

Figure 3: FTIR spectra of HEMA-co-AA hydrogel 

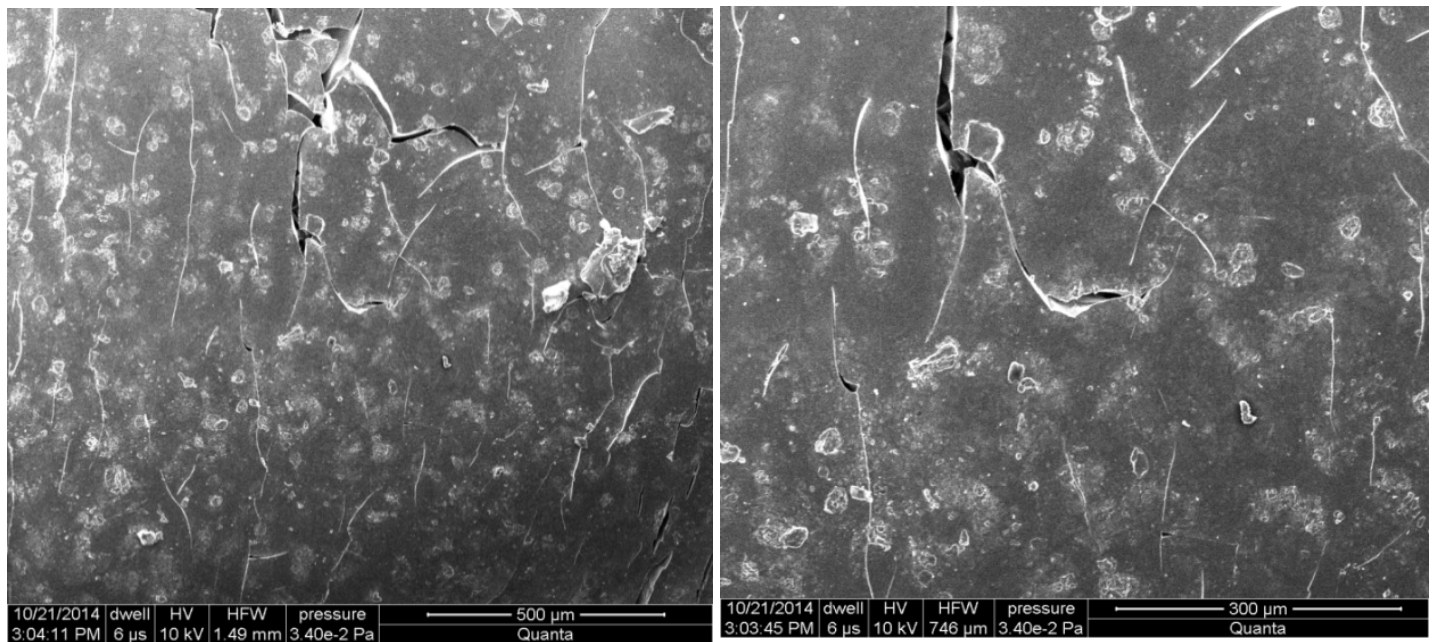

Figure 4: Scanning electron micrographs (SEM) of surface of HEMA-co-AA hydrogels at magnification of $100 \mathrm{X}$ and $200 \mathrm{X}$ respectively (left to right) and $500 \mu \mathrm{m}$ scale bar

\section{Thermal characteristics}

The thermal transition behavior of the formulations are shown in Figure 5. Formulated hydrogel (F4) was thermostable. Decomposition of formulation occurred in four steps. First, degradation was observed up to $275{ }^{\circ} \mathrm{C}$ with $21.17 \%$ weight loss due to dehydration. Second, another degradation took place from 275 to 400 ${ }^{\circ} \mathrm{C}$ with $35.28 \%$ weight loss and again, from 400 ${ }^{\circ} \mathrm{C}$ to $475{ }^{\circ} \mathrm{C}$ with $30.72 \%$ weight loss.

\section{DISCUSSION}

The swelling behavior of the hydrogels in different media is controlled by various factors such as equilibrium water content, $p K a$ value and chemical structure of formulation. At acidic $\mathrm{pH}$ carboxylic groups are protonated leading ionized groups in polymer chain. This results in no or less swelling of polymer network. At basic $\mathrm{pH}$ electrostatic repulsive forces between molecules resulted in expansion of polymeric network. [15]. In the present study, swelling ratio was varied by increasing monomer concentration (AA) from 15.013 to 16.420 because of higher hydrophilic content in polymer chain as depicted by formulation F4 to F6. Whereas swelling ratio was decreased by increasing cross linker concentration ranging from 10.104 to 8.775 due to the establishment of close-fitted network structure. However, this decrease with increase in swelling is statistically insignificant $(p<0.05)$.

Das also studied swelling behavior of hydrogels and stated that swelling ratio was increased by increasing monomer concentration due to increased hydration of polymeric network. Swelling ratio decreased with increasing crosslinker concentration due to more compact network formation [16].

The mechanism of this release can be attributed to swelling of the polymer ionic network. At low $\mathrm{pH}$, polymer ionizes resulting in formation of anionic centers which ultimately lead to domination of compact polymer interaction leading to a compact network. This constitutes hindrance to water penetration resulting in decreased water holding capacity and thus ultimately lowers drug release. At lower $\mathrm{pH} 1.2$, no noticeable difference in release profile was observed.

With increase in cross-linker concentration, ionization of carboxylic group occurs, resulting in formation of new crosslinked sections by hydrogen bonding. These electrostatic forces between functional groups result in compact arrangement of polymeric network. Ultimately, it leads to less swelling and low in vitro drug release [17].

Percent porosity was measured by pore volume present with in hydrogel structure while gel content was measured by cross linking density. With increasing concentration of HEMA and MBA percent porosity was decreased while percent gel content was increased. Increased gel content could be justified by enhanced cross linking density and greater physical entanglement resulting in less pore volume. As a result swelling ratio was decreased leading to decrease in in vitro drug release. Increased concentration of monomer AA resulted in less crosslinking density, leading to greater pore volume. As a result, water retention capacity and drug release increased. Shivani et al observed a similar pattern and explained that with increase in 

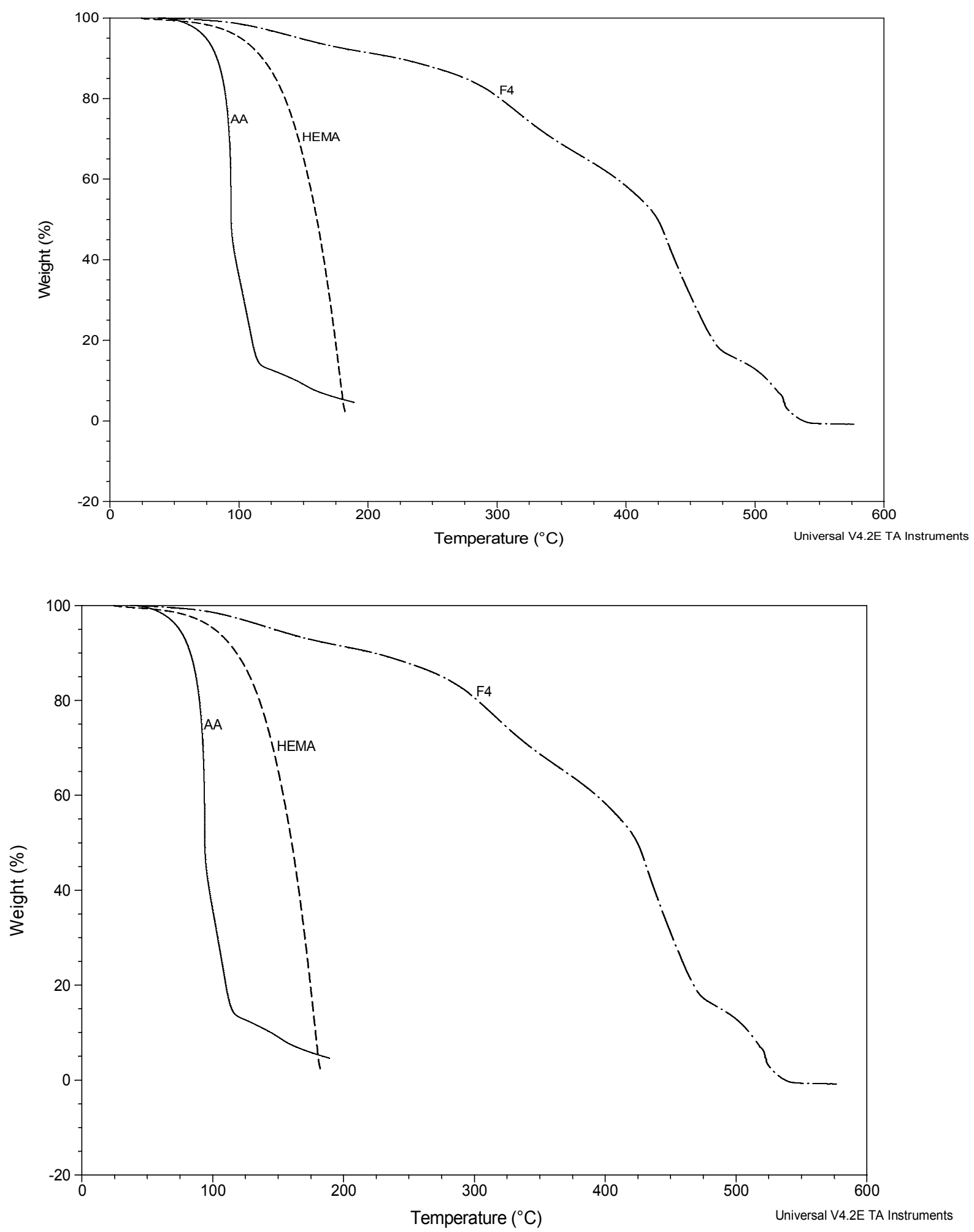

Figure 5: Thermal transition behavior of HEMA-co-AA hydrogel

crosslinking density, gel content rose while porosity decreased [18].

The results of this study also agree with those of a previous study where it was observed that porosity decreased with increase in crosslinking density [15].

Abdul \& Lila have sought to analyze the FTIR spectra of nicorandil and their findings are in agreement with those of the present study [20]. 
This porous structure is thought to be responsible for the swelling and drug release of the hydrogels. as these pores act as water channels and allow holding of water [18].

Decomposition of functional groups of the hydrogel is thought to be responsible for this degradation. Final degradation of hydrogel was observed at $550{ }^{\circ} \mathrm{C}$ with $20.71 \%$ weight loss. Das et al also found that the hydrogels were thermostable and displayed thermal decomposition in four distinct steps [16].

\section{CONCLUSION}

A hydrogel formulation of nicorandil for prolonged drug release, and hence a capability for decreased dosing frequency and improved patient compliance, has been successfully developed in vitro. However, in vivo studies are required to determine its suitability for clinical applications.

\section{ACKNOWLEDGEMENT}

The authors acknowledge Islamia University, Bahawalpur, Pakistan for providing support for this work.

\section{REFERENCES}

1. Gemma V, Judit TP, Fernando A. Polymers and Drug Delivery Systems. Curr Drug Deliv. 2012; 9: 1-28.

2. Kamel S, Ali N, Jahangir K, Shah SM, El-Gendy AA. Pharmaceutical significance of cellulose: $A$ review. Exp Polm Let. 2008; 2: 758-778.

3. Susheel K, Anil K, Kaith BS. Sunn hemp cellulose graft copolymers polyhydroxybutyrate composites:morphological and mechanical studies. Adv Mat Let. 2011; 2: 17-25.

4. Sabyasachi M, Somdipta R, Biswanath S. Polysaccharide based graft copolymers in controlled drug delivery. Int J Pharm Tech Res. 2010; 2: 1350-1358.

5. Marcela MG, Adriana MG, Isabela CC et al., Activity of nicorandil, a nicotinamide derivative with a nitrate group, in the experimental model of pain induced by formaldehyde in mice. Pharmacology, Biochemistry and Behavior. 2013; 106: 85-90.

6. Peppas NA, Barr-Howel BD. Characterization of cross linked structure of hydrogels, hydrogels in medicine and pharmacy fundamentals. Boca Raton. 1987; 1: 22-56.

7. Ranjha MN, Mudassir J, Sheikj ZZ. Synthesis and characterization of $\mathrm{pH}$ sensitive pectin/acrylic acid hydrogels for verapamil release study. Iran Polym J. 2011; 20: 147-159.

8. Nazar MR, Umbreen FQ. Preparation and characterization of crosslinked acrylic acid/hydroxypropyl methyl cellulose hydrogels for drug delivery. Int J Pharm Pharm Sci. 2014; 6: 400410.

9. Samiullah K, Nazar MR. Effect of degree of cross-linking on swelling and on drug release of low viscous chitosan/ poly(vinyl alcohol) hydrogels. Polym Bull. 2014; 71: 133-158.

10. Sudhair A, Bashir A, Zafar I, Shumaila B, Javid A. Study and evaluation of poly (n-vinyl-2-pyrrolidone) hydrogel swelling, theophylline loading and release. W App Sci J. 2013; 27: 236-249.

11. Liu ZL, Hu H, Zhuo RX. Konjac glucomannan graft acrylic acid hydrogels containing azo crosslinker for colon specific delivery. J Polym Sci A Polym Chem. 2004; 42: $370-380$.

12. Osiris WG, Manal THM. Thermal and structural studies of poly(vinyl alcohol) and hydroxypropyl cellulose blends. Nat Sci. 2012; 4: 57-67.

13. Richard AG, Haesun $P$, Kinam P. Pore structure of superporous hydrogels. Polym Adv Technol. 2000; 11: 617-625.

14. Fatemeh $A$, Rudabeh $V$, Rassoul D. Preparation of ethylcellulose coated gelatin microspheres as a multiparticulate colonic delivery system for 5aminosalicilic acid. Iran J Pharm Res. 2004; 2: 8186.

15. Nazar MR, Asadullah M, Abdullah AB, Nuzhat $T$, Saeed $A$, Hassan A. Preparation and characterization of isosorbide mononitrate hydrogels obtained by freeradical polymerization for site-specific delivery. Trop J Pharm Res. 2014; 13: 1979-1985.

16. Das M, Devi N, Sarma J. Preparation, characterization, and water sorption study of 2-acrylamido-2methylpropane sulfonic acid (AMPS) based hydrogel. J Chem Pharm Res. 2014; 6: 800-806.

17. Ojha Khyati, Shenoy Vranda, Gupta Saumya, Suseem $S R$. Formulation and evaluation of hydrogel with ascorbic acid using aloe vera gel powder as a drug carrier. Inn J Sci. 2013; 1: 18-20.

18. Shivani N, Nikhil S, Reddy BVK, Tanmay MS. Preparation and characterization of poly(vinyl alcohol) chondroitin sulphate hydrogel as scaffolds for articular cartilage regeneration. Ind J Mat Sci. 2013; 2: 1-8.

19. Sunitha S, Thirupathi A, Vijaya K. Preparation and evaluation of liposome entrapped hydrogel complex system of itraconazole for enhanced transdermal permeation. J pharm Sci Inn. 2014; 3: 25-29.

20. Abdul BA, Lila KN. Drug excipients compatibility studies of nicorandil in controlled release floating tablet. Int $J$ Pharm Pharm Sci. 2014; 6: 468-475. 